\title{
BIODIESEL DE MICROALGAS: AVANÇOS E DESAFIOS
}

\section{André Luiz Custódio Franco, Ivon Pinheiro Lôbo e Rosenira Serpa da Cruz*}

Departamento de Ciências Exatas e Tecnológicas, Universidade Estadual de Santa Cruz, Rod. Jorge Amado, km 16, 45662-000 Ilhéus - BA, Brasil

Cláudia Maria Luz Lapa Teixeira

Instituto Nacional de Tecnologia, Av. Venezuela, 82, 20081-312 Rio de Janeiro - RJ, Brasil

José Adolfo de Almeida Neto

Departamento de Ciências Agrárias e Ambientais, Universidade Estadual de Santa Cruz, Rod. Jorge Amado, km 16, 45662-000

Ilhéus - BA, Brasil

\section{Rafael Silva Menezes}

Secretaria de Desenvolvimento Tecnológico e Inovação, Ministério da Ciência, Tecnologia e Inovação, Esplanada dos Ministérios, Bloco E, 70067-900 Brasília - DF, Brasil

Recebido em 18/5/12; aceito em 17/9/12; publicado na web em 6/2/13

\begin{abstract}
BIODIESEL FROM MICROALGAE: PROGRESS AND CHALLENGES. Microalgae biomass has been described by several authors as the raw material with the greatest potential to meet the goals of replacing petroleum diesel by biodiesel while not competing with arable land suitable for food production. Research groups in different countries are seeking the most appropriate production model for productivity, economic viability and environmental sustainability. This review focused on recent advances and challenges of technology for the production of biodiesel from microalgae, including the procedures used to obtain biomass.
\end{abstract}

Keywords: bioenergy; biomass; microalgae.

\section{INTRODUÇÃO}

As projeções do U. S. Energy Information Administration (EIA), publicadas no relatório International Energy Outlook 2010, mostram que o consumo mundial total de energia comercializada aumentará em $49 \%$ entre 2007 e $2035 .{ }^{1}$ O estudo mostra que, dentre as fontes de energia, as renováveis terão o mais acelerado crescimento do consumo no período, atingindo 2,6\% ao ano. Tendência de alta nos preços do petróleo, preocupação com os impactos ambientais oriundos da utilização de combustíveis fósseis, bem como fortes incentivos governamentais para o aumento da utilização de energias renováveis em muitos países justificam as perspectivas para a expansão das fontes renováveis em todo o mundo. ${ }^{1}$

Eventos recentes têm intensificado o debate acerca da matriz energética mundial. Desde o final de 2010, é crescente a instabilidade política em países da região conhecida como mundo árabe, importante fornecedora de petróleo do mundo. Tensões decorrentes dos movimentos contra governos autoritários naquela região têm conduzido à instabilidade no fornecimento de petróleo por esses países. ${ }^{2}$

Os riscos associados a um acidente nuclear de grandes proporções, decorrente das catástrofes naturais ocorridas no Japão em março de 2011, reduziram as expectativas quanto à possibilidade de intensificação do uso da energia nuclear como uma estratégia na mitigação das emissões de gases intensificadores do efeito estufa antrópico da matriz energética mundial.

Os combustíveis derivados da biomassa assumem papel importante neste cenário. Dentre os combustíveis renováveis mais promissores destaca-se o biodiesel, uma mistura de ésteres metílicos ou etílicos de ácidos graxos, produzido pela reação de um óleo ou gordura com um álcool, na presença de um catalisador. O biodiesel pode ser usado puro ou em misturas com o diesel em motores ciclo diesel, sendo, em alguns aspectos, comparativamente menos poluente que o diesel. ${ }^{3}$

*e-mail: roserpa@uesc.br
Desde janeiro de 2010, os motoristas de todo o Brasil que abastecem seus veículos com combustível diesel fazem uso do B5 (5\% v/v biodiesel/diesel). A produção estimada de biodiesel no Brasil, em novembro de 2012, foi de $247 \mathrm{mil} \mathrm{m}^{3}$. No acumulado do ano, acrescido da estimativa para novembro, a produção atingiu $2.673 \mathrm{mil} \mathrm{m}^{3}$, um acréscimo de $0,7 \%$ em relação ao mesmo período de 2011 (2.456 mil $\mathrm{m}^{3}$ ). O Boletim DCR mostra ainda que, no mês de outubro, $72,7 \%$ do biodiesel brasileiro foram produzidos a partir de óleo de soja, 17,1\% de sebo bovino e $6,6 \%$ de óleo de algodão. ${ }^{4}$

O histórico da produção brasileira de biodiesel mostra que o setor está em crescente dependência de uma única matéria-prima, a soja, contrapondo-se ao objetivo do Programa Nacional de Produção e Uso do Biodiesel (PNPB) de sustentar sua cadeia na diversidade de materiais graxos disponíveis nas várias regiões do País.

Em meio ao predomínio dessas matérias-primas, o setor de bioenergia vive uma expectativa pela consolidação das microalgas como fonte viável de biomassa para a produção de biocombustíveis. De acordo com Chisti, ${ }^{5}$ estes micro-organismos fotossintetizantes são utilizados em aquicultura, para a produção de suplemento alimentar e para a extração de compostos de alto valor comercial, apresentando potencial para uso em biorremediação e biofertilização, assim como para a produção de vários tipos diferentes de biocombustíveis. Estes incluem o metano produzido pela digestão anaeróbia da biomassa das microalgas, ${ }^{6}$ o biodiesel derivado do óleo de microalgas, ${ }^{7} \mathrm{o}$ bio-hidrogênio produzido por processos fotobiológicos, ${ }^{8} \mathrm{o}$ bio-óleo resultante da pirólise ${ }^{9}$ e o bioetanol. ${ }^{10}$ Vale ressaltar que, para alguns dos usos acima citados, já existe produção comercial de microalgas, ${ }^{11}$ o que demonstra sua viabilidade econômica nestes casos.

Com base nos principais produtores mundiais, estima-se que a produção atual de biomassa algal seja de 38 milhões de L, concentrados principalmente na China, Japão, Taiwan, Estados Unidos e Índia. Considerando-se que o teor médio de óleo em microalgas é de $30 \%$, existe um potencial de 11,4 milhões de L para a produção de biodiesel. ${ }^{12}$ 
Em relação aos vegetais superiores, as microalgas apresentam maior eficiência fotossintética, como pode ser observado na Tabela 1, onde também são apresentadas as médias de produtividade de biomassa em barris equivalentes de petróleo (bep) por hectare por ano, para algumas culturas utilizadas na produção de biocombustíveis, obtidas por extrapolação dos resultados encontrados em escala de laboratório. A eficiência fotossintética foi calculada com base em uma estimativa de 10 mil bep de energia solar média por hectare por ano. A cana-de-açúcar é a única cultura tradicional que tem uma eficiência acima de $1 \%$. As microalgas apresentam, portanto, potencial produtivo destacado. ${ }^{13}$

Tabela 1. Produção de energia e eficiência fotossintética de diferentes fontes de biomassa. Adaptada da ref. 13

\begin{tabular}{lccc}
\hline $\begin{array}{l}\text { Fonte de } \\
\text { biomassa }\end{array}$ & $\begin{array}{c}\text { Tipo de combustí- } \\
\text { vel produzido }\end{array}$ & $\begin{array}{c}\text { Produtividade } \\
\left(\text { bep ha }^{-1} \text { ano }^{-1}\right)\end{array}$ & $\begin{array}{c}\text { Eficiência } \\
\text { fotossintética }(\%)\end{array}$ \\
\hline Milho & Etanol & 20 & 0,2 \\
Cana-de-açúcar & Etanol & $210-250$ & $2-3$ \\
Soja & Biodiesel & $13-22$ & $0,1-0,2$ \\
Girassol & Biodiesel & $8,7-16$ & $0,1-0,2$ \\
Microalgas & Biodiesel & $390-700$ & $4-7$ \\
\hline
\end{tabular}

A eficiência das microalgas no armazenamento de energia solar, através da produção de compostos orgânicos via processo fotossintético, seus elevados rendimentos em biomassa e em frações lipídicas obtidas em cultivo controlado, seu rápido crescimento, a utilização de terras e recursos de baixo custo de oportunidade, a não competição com alimentos, além do sequestro de $\mathrm{CO}_{2}$, todos estes fatores favoráveis despertaram uma onda de investimentos em pesquisa e desenvolvimento de tecnologias que buscam principalmente vencer as barreiras econômicas e ambientais desta nova oportunidade para o setor de energias renováveis. ${ }^{14}$

O objetivo deste trabalho foi abordar os principais avanços e desafios da tecnologia de produção da biomassa de microalgas com vistas à produção de biodiesel.

\section{HISTÓRICO DAS INICIATIVAS DE PRODUÇÃO DE BIODIESEL DE MICROALGAS}

De 1978 a 1996, o Escritório de Desenvolvimento de Combustíveis do Departamento de Energia norte-americano financiou o Aquatic Species Program (ASP) para desenvolver combustíveis de transporte renováveis a partir de microalgas. $\mathrm{O}$ foco principal do programa foi a produção de biodiesel a partir de microalgas com alto teor de lipídeos, cultivadas em tanques, utilizando $\mathrm{CO}_{2}$ residual. Ao longo de quase duas décadas deste programa, foram feitos grandes avanços na técnica de manipulação do metabolismo de microalgas e na engenharia de sistemas de produção das mesmas. As atividades do programa e os resultados obtidos são apresentados em relatório publicado em 1998. ${ }^{15}$ Naquela época não foi possível viabilizar economicamente a produção da biomassa microalgal para a produção de biodiesel, principalmente devido à alta variação da produtividade em óleo ao longo do ano.

No Japão foi desenvolvido um programa com objetivo semelhante pelo Research Institute of Innovative Technology (RITE), porém substituindo o sistema aberto pelo cultivo em fotobiorreatores, mais intensivo, com maiores possibilidades de controle e uma maior produtividade de biomassa por área quando comparado ao sistema aberto. ${ }^{16}$ Neste programa também não se alcançou uma viabilidade econômico-financeira para a produção da biomassa microalgal.

No Brasil, o Ministério da Ciência, Tecnologia e Inovação (MCTI), em parceria com a Secretaria Especial de Aquicultura e
Pesca (SEAP/PR), lançou em 2008, através do Conselho Nacional de Desenvolvimento Científico e Tecnológico (CNPq), edital de pesquisa com o objetivo de selecionar projetos voltados para a aquicultura e uso de microalgas para a produção de biodiesel, no valor total de R\$ 4,5 milhões. Foram apresentadas 63 propostas de projetos de PD\&I, os quais abordaram, dentre outros aspectos, desenvolvimento de técnicas de cultivo; maximização da produtividade em óleo; avaliação da viabilidade econômica do processo global, do cultivo à obtenção de biodiesel; processos mais econômicos e eficientes para a coleta da biomassa algal e a extração da fração lipídica; avaliação das propriedades físico-químicas de biodiesel de microalgas e adoção de estratégias, visando garantir com que atendam às especificações de qualidade definidas nas resoluções da ANP. ${ }^{17}$

Outra ação do MCTI teve início em novembro de 2010, com a aprovação do Projeto MCT/FINEP de "Produção de biodiesel derivado de óleos de microalgas". Com conclusão prevista para o final de 2012 e investimento de R $\$ 6$ milhões, o projeto, que tem apoio da Rede Brasileira de Tecnologia do Biodiesel, reúne diferentes institutos de pesquisa e universidades do País com atuação na área de aquicultura e biodiesel, tais como a Universidade Federal de São Carlos (UFSCar), Universidade Federal do Espírito Santo (UFES), Universidade Federal da Paraíba (UFPB), Instituto Nacional de Tecnologia (INT), Universidade Federal do Paraná (UFPR), Universidade Federal do Rio de Janeiro (UFRJ), Universidade Federal de Goiás (UFG), Instituto de Tecnologia do Paraná (Tecpar) e Universidade Federal de Lavras (UFLA). Estes dados mostram que existem esforços em PD\&I no Brasil, o que pode resultar em avanços significativos nesta temática a curto e médio prazos. ${ }^{17}$

\section{BIOSSÍNTESE DE LIPÍDEOS}

O rendimento da produção de biodiesel depende principalmente do conteúdo de óleo nas células das microalgas. A Tabela 2 mostra o conteúdo e a produtividade de óleo na base seca encontrada em diferentes espécies de microalgas. ${ }^{18}$

Tabela 2. Conteúdo e produtividade de óleo de algumas espécies de microalgas. Adaptada da ref. 19

\begin{tabular}{lcc}
\hline Espécies de microalgas & $\begin{array}{c}\text { Conteúdo de óleo } \\
(\% \text { da matéria seca) }\end{array}$ & $\begin{array}{c}\text { Produtividade de óleo } \\
\left(\mathrm{m} \mathrm{L} \mathrm{L} \mathrm{d}^{-1}\right)\end{array}$ \\
\hline Chlorella protothecoides & $23-55$ & 1214 \\
Chlorella vulgaris & $5-50$ & - \\
Chlorella sorokiniana & $19-22$ & 45 \\
Nannochloropsis oculata & $22-30$ & $84-142$ \\
Dunaliella salina & $14-20$ & 116 \\
Neochloris oleoabundans & $35-65$ & $90-134$ \\
Phaeodactylum tricornutum & $18-57$ & 45 \\
Spirulina maxima & $4-9$ & - \\
Chlorococcum sp. & 19 & 54 \\
\hline
\end{tabular}

Apesar dos valores expressivos no percentual de lipídeos de várias microalgas, é possível aumentar estes valores a fim de auxiliar a viabilização econômica da produção de biodiesel a partir do óleo de microalgas. Este resultado pode ser obtido através da aplicação de condições de stress (deficiência de nutrientes, anaerobiose, temperaturas extremas) na fase de crescimento da biomassa microalgal. ${ }^{13}$

Em condições adversas na natureza ou em sistemas de cultivo, se a densidade de células não é muito alta, a fotossíntese ainda é possível. ${ }^{19}$ Embora o crescimento real e a produção de biomassa nestas condições sejam limitados, as células ainda são capazes de 
fixar $\mathrm{CO}_{2}$ e acumular amido ou lipídeos, substâncias importantes para garantir a sobrevivência em condições ambientais desfavoráveis ou de stress. Algas que armazenam lipídeos em grandes quantidades são muitas vezes encontradas em ambientes e microclimas que alternam frequentemente entre as condições ideais para seu crescimento e sobrevivência, por um lado, e condições abaixo do ideal, por outro. ${ }^{13}$

Assim, condições de stress são estrategicamente utilizadas em cultivos que tenham a finalidade de produzir lipídeos ou outras moléculas de interesse comercial. Nestas condições, porém, como decorrência da limitação do crescimento, a produtividade em biomassa é reduzida e, por conseguinte, a produtividade geral em óleo não acompanha o aumento no teor de óleo, podendo até diminuir. ${ }^{20}$

Com o propósito de contornar o problema de uma possível baixa produtividade geral em óleo, as condições de stress são aplicadas numa segunda etapa de cultivo, após uma primeira etapa em que se oferecem condições apropriadas ao máximo crescimento celular. Neste sentido, Jiang e colaboradores ${ }^{21}$ estudaram o cultivo de Nannochloropsis sp. em duas etapas, utilizando a privação de nitrogênio como condição de stress, numa segunda etapa. Nestes cultivos, a fim de reduzir o custo de produção da biomassa, utilizou-se uma mistura de água do mar e água residual municipal como meio de cultivo e $\mathrm{CO}_{2}$ residual como fonte de carbono. Foi observado um aumento na concentração celular e no teor de lipídeos, de 0,71 para 2,23 $\mathrm{g} \mathrm{L}^{-1}$ e de 33,8 para 59,9\%, respectivamente, após 12 dias de cultivo na segunda fase, utilizando-se um percentual de $50 \%$ de água residual municipal e aeração com $15 \%$ de $\mathrm{CO}_{2}$.

No entanto, é importante ressaltar que, além da produtividade em óleo, outros fatores devem ser avaliados para a escolha das microalgas mais adequadas à produção de biodiesel. Entre eles, vale ressaltar a composição em ácidos graxos; a capacidade de crescimento em condições ambientais específicas; os requisitos de coleta, extração e purificação do óleo, balanço energético favorável e a possibilidade de uso como matéria-prima para produção de outros produtos nas indústrias de alimentos, cosméticas e de fármacos. ${ }^{22}$ Alguns destes requisitos serão aprofundados ao longo desta revisão.

\section{REQUISITOS PARA O CRESCIMENTO DE MICROALGAS}

As microalgas necessitam de uma fonte de energia, seja a energia luminosa para o crescimento autotrófico ou um composto orgânico para o crescimento heterotrófico. Entre estes dois extremos, existem rotas tróficas intermediárias, ${ }^{23}$ conforme será apresentado na seção "Modalidades de cultivo".

$\mathrm{O}$ crescimento autotrófico tem como fonte de carbono o $\mathrm{CO}_{2}$ ou o $\mathrm{HCO}_{3}{ }^{-}$dissolvido na água, mas ainda requer outros nutrientes, especialmente os macro (NPK) e micronutrientes (metais), além de vitaminas, em certos casos. ${ }^{24} \mathrm{~A}$ temperatura e o $\mathrm{pH}$ devem estar na faixa de tolerância da microalga cultivada, que pode variar bastante entre gêneros e até espécies. ${ }^{25}$

As microalgas, em sua diversidade, são organismos muito flexíveis quanto ao habitat, sendo encontradas tanto em ambientes úmidos terrestres, quanto em ambientes aquáticos de água doce, salobra e salgada. ${ }^{26}$ Esta capacidade proporciona vantagens consideráveis em comparação com os cultivos convencionais utilizados para a produção de biodiesel, com potencial de minimizar o uso e os impactos ambientais adversos nos recursos naturais solo e água.

\section{MODALIDADES DE CULTIVO}

As microalgas podem ser cultivadas nos modos autotrófico, heterotrófico e mixotrófico, sendo que a diferença entre estas modalidades de cultivo está na fonte de energia e de carbono. No cultivo autotrófico, mais especificamente, fotoautotrófico, as células obtêm energia da luz e o carbono do $\mathrm{CO}_{2}$ do ar, produzindo então, através da fotossíntese, suas biomoléculas: polissacarídeos, proteínas, lipídeos e ácidos nucleicos. No cultivo heterotrófico, as células utilizam compostos orgânicos como fonte de energia e de carbono e, no mixotrófico, usam a luz, compostos orgânicos e inorgânicos como fonte de energia e $\mathrm{CO}_{2}$ e compostos orgânicos como fonte de carbono. ${ }^{21}$

Sobre cultivos heterotróficos e mixotróficos existe uma quantidade bem menor de dados do que sobre os cultivos autotróficos, uma vez que naqueles cultivos são utilizadas fontes de carbono orgânico, o que traz preocupação acerca de uma possível competição pelo uso destas matérias-primas, voltadas também para a alimentação humana. Por outro lado, a vantagem associada aos cultivos heterotrófico e mixótrófico ${ }^{27}$ é a possibilidade de se aumentar a produtividade em biomassa e em lipídeo, o que motiva as pesquisas sobre o tema. Convém ressaltar que no modo heterotrófico somente algumas microalgas são capazes de crescer sem que seja feita alguma manipulação genética.

No caso do cultivo autotrófico, um aspecto bastante positivo é o uso de $\mathrm{CO}_{2}$ resultante de processos industriais, o que representa uma forma de mitigação das emissões de gases de efeito estufa, além da diminuição dos custos de produção da biomassa microalgal. Usinas a carvão emitem gases que podem conter até $13 \%$ de $\mathrm{CO}_{2}{ }^{28}$ e podem ser uma fonte interessante de $\mathrm{CO}_{2}$ residual, assim como alguns processos industriais que liberam $\mathrm{CO}_{2}$ como, por exemplo, a produção de etanol. ${ }^{29}$ Desta forma, a estratégia de aliar os cultivos de microalgas aos processos citados pode ser uma alternativa viável para reciclar o $\mathrm{CO}_{2}$ residual e, além disto, contribuir para a viabilização econômica da produção de biodiesel.

No cultivo autotrófico, apesar de sua alta eficiência em utilizar a luz, as microalgas apresentam um crescimento lento devido à limitação de luz em condições de larga escala, quando se alcançam altas densidades de células, ou "fotoinibição" devido à luz excessiva. ${ }^{30} \mathrm{O}$ crescimento heterotrófico, por outro lado, elimina o requerimento por luz e oferece a possibilidade de aumentar significativamente a concentração celular e a produtividade de biomassa em larga escala. ${ }^{31}$ Por exemplo, embora a microalga verde $C$. protothecoides cresça fotoautotroficamente ou heterotroficamente, o crescimento heterotrófico usando acetato, glicose ou outros compostos orgânicos como fonte de carbono resulta em maior produção de biomassa. ${ }^{32}$

O cultivo mixotrófico é também uma alternativa à produção fotoautotrófica de microalgas. Cid e Abalde ${ }^{33}$ observaram maiores taxas de crescimento e concentração de biomassa no cultivo mixotrófico em relação ao cultivo autotrófico de Tetraselmis suecica. HerediaArroyo e colaboradores ${ }^{34}$ estudaram as três modalidades de cultivo de $C$. protothecoides e observaram maiores taxas de crescimento e de concentração celular máxima em cultivos heterotrófico e mixotrófico em relação ao autotrófico, não havendo diferença entre os cultivos heterotrófico e mixotrófico. No que diz respeito ao teor em lipídeos, estes autores não observaram diferenças entre os diferentes tipos de cultivo; resultado diverso foi encontrado por Miao e $\mathrm{Wu},{ }^{35} \mathrm{Xu}$ e colaboradores ${ }^{36}$ e Li e colaboradores, ${ }^{37}$ que observaram diferença no teor de lipídeo entre os cultivos heterotrófico e o autotrófico. Argumentaram que estas diferenças podem ter sido geradas por diferenças nas condições de cultivo empregadas nos diferentes trabalhos.

O aumento no teor de lipídeo em cultivo heterotrófico, observado pelos autores citados, é outra vantagem deste tipo de cultivo em relação ao autotrófico, no caso da produção de biomassa microalgal para a geração de biodiesel. Liang e colaboradore ${ }^{38}$ confirmaram uma maior produtividade global em lipídeos para os cultivos heterotróficos com relação ao cultivo autotrófico. Apesar do percentual de lipídeos ter sido menor no cultivo heterotrófico, a maior produtividade em biomassa neste tipo de cultivo gerou uma maior produtividade geral em lipídeo.

Se, por um lado, o teor de lipídeos e sua produtividade podem ser aumentados no cultivo heterotrófico, existem evidências de 
diminuição nos teores de proteína, clorofila e carotenoides. ${ }^{39}$ Uma saída seria utilizar o cultivo mixotrófico, em que se tem o estímulo da luz. No entanto, em altas concentrações celulares a luz se torna limitante e a contribuição do crescimento fotoautotrófico para a taxa de crescimento global é muito baixa, com consequente diminuição na produção de proteína e clorofila no cultivo mixotrófico em relação ao cultivo autotrófico. ${ }^{40}$ Para contornar este problema, foi sugerido por Ogbonna e colaboradores ${ }^{41}$ um cultivo sequencial heterotrófico-autotrófico, no qual o $\mathrm{CO}_{2}$ gerado na fase heterotrófica foi usado na fase autotrófica. Nestas condições, foi possível obter uma concentração celular (14 $\left.\mathrm{g} \mathrm{L}^{-1}\right)$ bem mais alta que a do cultivo autotrófico realizado em trabalhos anteriores e uma produtividade em biomassa muito elevada ( $\left.4 \mathrm{~g} \mathrm{~L}^{-1} \mathrm{dia}^{-1}\right)$, com conteúdo em proteína e clorofila similar ao obtido em cultivos autotróficos.

Com o objetivo de reduzir o custo de produção de biodiesel a partir de microalgas utilizando o cultivo heterotrófico, fontes de carbono mais baratas têm sido consideradas, como o uso de águas residuárias e, neste caso, o benefício é múltiplo, pois estas têm a sua carga de nitrogênio e fósforo diminuída. ${ }^{42} \mathrm{~A}$ alga $S$. limacinum mostrou ser capaz de crescer em glicerol bruto, derivado da produção de biodiesel. ${ }^{43} \mathrm{~A}$ biomassa seca apresentou $51 \%$ de lipídeos, $14 \%$ de proteínas, $24 \%$ de carboidratos e $11 \%$ de cinzas. Os resultados deste trabalho apontaram que o glicerol bruto derivado do biodiesel é uma matéria-prima promissora para a cultura heterotrófica de microalgas, o que é corroborado por outros trabalhos. ${ }^{38}$

Um modelo de fotossíntese-fermentação foi proposto, visando a fusão dos aspectos positivos de cultivos autotróficos e heterotróficos, principalmente no que diz respeito às mais altas produtividades em biomassa e percentagens em lipídeos totais alcançadas em cultivos heterotróficos e o uso de $\mathrm{CO}_{2}$ proveniente de emissões industriais. A microalga Chlorella protothecoides foi cultivada em modo autotrófico para a fixação de $\mathrm{CO}_{2}$ e depois cultivada heterotroficamente para promover o acúmulo de óleo, utilizando-se glicose como fonte de carbono. Comparado ao metabolismo heterotrófico típico, foi alcançada uma produção de lipídeos $69 \%$ superior na fase de fermentação do cultivo. Além disto, neste novo modelo a liberação de $\mathrm{CO}_{2}$ foi $66,7 \%$ menor do que no metabolismo heterotrófico típico. Os autores concluíram que o modelo de fotossíntese-fermentação com dupla fixação de $\mathrm{CO}_{2}$ nas etapas de fotossíntese e fermentação aumenta a razão de conversão do carbono de açúcar para óleo, fornecendo, portanto, uma abordagem eficiente para a produção de lipídeos de microalgas. ${ }^{44}$

\section{SISTEMAS DE CULTIVO}

A utilização do óleo de microalgas para a produção de biodiesel demanda um aumento na escala de cultivo, seja em sistemas abertos ou fechados, uma vez que quase a totalidade dos trabalhos publicados foi desenvolvida em escala de laboratório. Dentro deste contexto, Moazami e colaboradores ${ }^{45}$ investigaram a produção em larga escala de Nannochloropsis sp., em lagoas abertas de 2000 L de capacidade em ambiente coberto. Como um dos parâmetros que mais influenciaram a produtividade em biomassa e o teor de lipídeos em tanques de lagoas abertas foi a distribuição uniforme dos nutrientes e do $\mathrm{CO}_{2}$, os autores analisaram o efeito da velocidade das pás sobre a produtividade em biomassa. Os parâmetros meio de crescimento, iluminação, $\mathrm{pH}$, nível de água e temperatura foram mantidos constantes. A produtividade máxima em biomassa (46 $\left.\mathrm{g} \mathrm{L}^{-1} \mathrm{~m}^{-2}\right)$ e maior teor de lipídeos $(52 \%)$ foram alcançados após 14 dias e com velocidade das pás de 2,1 $\mathrm{rad} \mathrm{s}^{-1}$.

\section{Cultivo aberto}

Grande parte dos cultivos de microalgas tem sido realizada em lagoas e tanques abertos que utilizam a luz solar e o $\mathrm{CO}_{2}$ da atmosfera.
Os tanques podem ser construídos e explorados a baixos custos e, portanto, oferecem muitas vantagens, desde que sejam utilizadas espécies adequadas para este tipo de cultivo. ${ }^{46}$ Os tanques têm uma variedade de formas e tamanhos possíveis, sendo o tipo comumente usado o raceway (tipo pista de corrida).

Pelo fato de nenhum material transparente ser necessário na construção de tanques abertos, uma gama muito ampla de materiais pode ser empregada. Esses tanques são também de manutenção relativamente fácil, uma vez que se tem acesso livre para realizar a limpeza do biofilme que se acumula sobre as superfícies. A principal desvantagem dos sistemas abertos é que ocorre evaporação da água a uma taxa similar às culturas terrestres e, também, são mais suscetíveis à contaminação por espécies indesejáveis. Inicia-se o cultivo com uma espécie que é inoculada no tanque, mas ao longo do tempo espécies indesejáveis são inevitavelmente introduzidas e podem reduzir severamente o rendimento e até mesmo superar as espécies inoculadas, pois, uma vez que um concorrente importante tiver estabelecido residência no tanque, torna-se extremamente difícil erradicá-lo.

No entanto, um cultivo sustentável e confiável de uma única espécie em sistemas abertos pode ser incentivado através do cultivo de espécies extremófilas, que toleram condições extremas de temperatura, $\mathrm{pH}$ ou salinidade. Spirulina platensis e Spirulina máxima, por exemplo, sobrevivem e crescem bem em $\mathrm{pH}$ alto $(9$ a 11,5), tornando-se geralmente espécie dominante nestes ambientes. ${ }^{47}$ Dunaliella salina cresce muito bem em águas altamente salinas, devido a seu alto conteúdo de glicerol intracelular, que assegura uma proteção contra a pressão osmótica. ${ }^{48}$ Assim, estas microalgas são cultivadas com êxito em escala comercial em sistemas abertos.

\section{Cultivo fechado}

O termo "fechado" diz respeito ao menor contato com o ambiente externo que estes sistemas apresentam em relação aos tanques. Os sistemas fechados são comumente denominados fotobiorreatores e geralmente são utilizados para produção em larga escala, gerando produtos de alto valor comercial. A vantagem comparativa destes sistemas em relação aos sistemas abertos é a obtenção de maiores produtividades de biomassa microalgal, bem como a possibilidade de maior controle das condições de cultivo. ${ }^{48}$

Os fotobiorreatores são classificados em "tubulares" e "planares", de acordo com a geometria do compartimento que encerra a cultura. Assim, são constituídos de tubos ou placas de material transparente à luz visível.

Nestes sistemas, o controle das condições de cultivo é mais fácil e o potencial de contaminação é menor em comparação com os sistemas abertos, como resultado da menor exposição da cultura ao ambiente. As placas e os tubos são confeccionados de maneira que o caminho óptico seja menor em comparação àquele dos tanques, promovendo uma melhor distribuição da luz e, por conseguinte, uma maior produtividade em biomassa. Contudo, os custos de implementação e de operação destes sistemas são superiores aos dos tanques. ${ }^{49}$

A Tabela 3 mostra vantagens e desvantagens dos sistemas de produção abertos e fechados para os principais parâmetros. ${ }^{50}$

\section{COLETA E SEPARAÇÃO DA BIOMASSA}

Na produção de microalgas para uso na aquicultura, estas são usadas diretamente em conjunto com o seu meio de crescimento. Em outros casos, no entanto, como no uso da biomassa seca (acondicionada em cápsulas ou na forma de comprimidos), na extração de pigmentos e na produção de biodiesel, há a necessidade de separação da biomassa microalgal do meio de crescimento. 
Tabela 3. Vantagens e desvantagens dos sistemas de cultivo aberto e fechado de microalgas. Adaptada da ref. 41

\begin{tabular}{|c|c|c|}
\hline Parâmetro & $\begin{array}{l}\text { Tanques } \\
\text { (raceway) }\end{array}$ & $\begin{array}{l}\text { Sistemas fechados } \\
\text { (fotobiorreatores) }\end{array}$ \\
\hline Espaço requerido & muito & pouco \\
\hline Risco de contaminação & alto & médio a baixo \\
\hline Perdas de água & alto & baixo \\
\hline Concentração de oxigênio & usualmente baixa & $\begin{array}{l}\text { deve ser removido } \\
\text { continuamente }\end{array}$ \\
\hline $\mathrm{CO}_{2}$-perdas & alto & quase nenhuma \\
\hline $\begin{array}{l}\text { Reprodutibilidade da } \\
\text { produção }\end{array}$ & $\begin{array}{l}\text { variável, mas } \\
\text { consistente }\end{array}$ & $\begin{array}{c}\text { possível dentro de } \\
\text { determinadas tolerâncias }\end{array}$ \\
\hline Controle do processo & limitado & possível \\
\hline $\begin{array}{l}\text { Desgaste do material de } \\
\text { construção }\end{array}$ & baixo & usualmente alto \\
\hline $\begin{array}{l}\text { Dependência de condições } \\
\text { climáticas }\end{array}$ & alto & menor, por ser protegido \\
\hline Temperatura & variável & necessário resfriamento \\
\hline Custo de colheita & alto & médio \\
\hline Manutenção & fácil & difícil \\
\hline Custos de construção & médio & alto \\
\hline $\begin{array}{l}\text { Concentrações de biomassa } \\
\text { na colheita }\end{array}$ & baixo & alto \\
\hline
\end{tabular}

Não há um método padrão para a coleta e separação das microalgas. Estas podem ser separadas do meio líquido em escala comercial por centrifugação, sendo que a floculação e a flotação podem ser usadas como métodos coadjuvantes.

A escolha do método é baseada nas características da microalga em questão, no tipo de cultivo e no uso da biomassa, entre outros aspectos. No caso de algumas microalgas, tais como Arthrospira sp., as células são relativamente grandes e é fácil separar a biomassa da água por filtração. ${ }^{51}$ Outro aspecto importante considerado na escolha do método de separação da biomassa é o custo. Em geral, este custo representa de 20 a $30 \%$ do total da produção da biomassa. ${ }^{52}$

A centrifugação é um método que tem sido aplicado com sucesso para a separação das células de microalgas, por ser bastante eficiente, mas apresenta algumas desvantagens. Em primeiro lugar, o processo envolve a exposição das células de microalgas a elevadas forças gravitacionais e de cisalhamento, que podem danificar a estrutura celular. Em segundo lugar, apresenta altos custos e alta demanda de energia, ${ }^{53}$ sendo, portanto, adequado apenas para produtos de alto valor comercial. ${ }^{54}$ Processos alternativos vêm sendo estudados, como a filtração, ${ }^{55}$ a microfiltração/ultrafiltração com membranas, ${ }^{55}$ a eletrocoagulação ${ }^{56}$ e a biofloculação. ${ }^{57}$

A coagulação envolve ajuste de $\mathrm{pH}$ ou adição de eletrólitos, enquanto a floculação envolve a adição de polímeros catiônicos, apesar destes termos serem geralmente utilizados sem nenhuma diferenciação. ${ }^{51}$ Essas abordagens (floculação/coagulação) são muito convenientes e complementares a outros processos, possibilitando um tratamento rápido de grandes quantidades de cultura, diminuindo consideravelmente o volume a ser processado posteriormente por centrifugação.

Sais de alumínio e de ferro são usados como agentes coagulantes/ floculantes em tratamento de água e, por conseguinte, são usados também para flocular microalgas. ${ }^{58}$ Estas substâncias, porém, podem trazer dificuldades para o uso posterior da biomassa microalgal por conta da toxicidade destes compostos; já a eletrofloculação e a biofloculação, por exemplo, não apresentam este inconveniente, assim como a floculação obtida por variação no $\mathrm{pH} .{ }^{59}$
Há ainda métodos de floculação alternativos eficientes como, por exemplo, a biofloculação mediada por bactérias, cujo percentual de recuperação da biomassa pode chegar a 90\% ${ }^{60}$ Entre os agentes floculantes alternativos, que atendam aos requisitos de baixo custo de obtenção, baixa toxicidade e fácil disponibilidade, a semente de Moringa demonstrou ser uma boa opção. Em ensaios de floculação com Chlorella vulgaris, foi obtido um percentual de diminuição da densidade ótica (em $730 \mathrm{~nm}$ ) de 83\%, para uma concentração de $0,1 \mathrm{~g} \mathrm{~L}^{-1}$ de semente triturada adicionada diretamente à cultura. ${ }^{61} \mathrm{O}$ percentual de diminuição da densidade ótica $(e m 730 \mathrm{~nm})$ representa indiretamente o percentual de floculação.

É importante também avaliar o efeito do floculante utilizado na composição em ácidos graxos do óleo da microalga obtido. Foi verificada uma diferença no perfil em ácidos graxos das microalgas Nannochloropsis oculata e Thalassiosira weissflogii quando floculada por hidróxido de sódio e pelo floculante Magnafloc LT-25, e por hidróxido de sódio com o floculante Flopam. ${ }^{62}$

Enfim, entre os processos existentes para a separação da biomassa microalgal com vistas à pré-concentração para redução dos custos das etapas subsequentes, a floculação tem sido escolhida como o processo mais vantajoso devido à menor demanda energética. ${ }^{63}$ Para a produção em grande escala, no entanto, ainda existe a necessidade de desenvolvimento de processos energeticamente eficientes e com menor custo.

Após a separação da biomassa microalgal do seu meio de crescimento, algumas vezes são necessários outros processos com o objetivo de melhorar a eficiência da etapa de extração do óleo, a qual é muito importante para a produção de biodiesel. Estes processos consistem na ruptura da estrutura celular (ultrassom, micro-ondas, autoclave, homogeneização a altas pressões, moinho de pérolas etc.), seguida de secagem (aquecimento, resfriamento, spray) e redução do tamanho das partículas (moagem e peneiração). Halim e colaboradores ${ }^{64}$ publicaram um excelente artigo de revisão sobre métodos de extração de óleo de microalgas para a produção de biodiesel, em que discutem a importância destas etapas de pré-tratamento para uma melhor eficiência durante a extração do óleo.

\section{EXTRAÇÃO E CARACTERIZAÇÃO DO ÓLEO}

A extração do óleo de microalgas representa uma etapa de alta demanda energética, pois, na maioria das vezes, é necessária a remoção da água (meio de cultivo). Esta etapa pode representar, juntamente com a etapa de separação da biomassa (colheita), uma parcela significativa na viabilidade econômica do processo de produção de biodiesel, estes custos podem variar de 3,3 a 30\%, dependendo da morfologia das espécies e do tipo de cultivo. ${ }^{65}$

Diversos tipos de lipídeos são produzidos pelas microalgas e a distribuição destes nas células depende da espécie, assim como das condições de cultivo. ${ }^{66}$ Estes lipídeos incluem fosfolipídeos, glicolipídeos, mono-, di- e triacilgliceróis, dentre outros. ${ }^{67}$ Dentre os tipos de lipídeos extraídos das microalgas apenas os triacilgliceróis são facilmente convertidos em biodiesel pelo método de transesterificação, o mais adotado comercialmente. Diversos autores têm trabalhado na prospecção de microalgas adequadas para a produção de biodiesel e para isso concentram seus trabalhos, além do cultivo, da colheita e separação das microalgas, nos processos de extração e caracterização da fração lipídica extraída. ${ }^{68}$

Diante deste contexto, o método de extração de lipídeos da biomassa microalgal para este fim deve ser o mais específico e seletivo possível, a fim de minimizar a extração das frações não lipídicas e maximizar as frações desejadas. ${ }^{69}$ Alternativamente, as frações não lipídicas coextraídas (proteínas, polissacarídeos e pigmentos) podem ser aproveitadas nas indústrias de fármacos e alimentos, o que pode 
representar benefícios econômicos para viabilizar a produção de biodiesel.

Procedimentos consagrados para extração de óleo de sementes vegetais, tais como prensagem e extração por solventes químicos, além da combinação dos dois métodos, têm sido adaptados às microalgas. Outros métodos também têm sido avaliados em escala de laboratório: extração com $\mathrm{CO}_{2}$ em estado supercrítico ${ }^{70}$ extração com enzimas, ${ }^{71}$ extração assistida por ultrassom ${ }^{72}$ e por micro-ondas. ${ }^{73}$

A composição dos lipídeos extraídos de microalgas depende em parte do solvente empregado na sua extração ${ }^{64}$ Assim, a técnica de extração é fundamental não apenas para o processo produtivo, mas também para a avaliação da qualidade do óleo.

Métodos gravimétricos baseados na extração com hexano em Soxhlet ou no método de Bligh e Dyer (extração com mistura clorofórmio/metanol) são comumente empregados para determinação do teor de lipídeos totais. ${ }^{74}$ Ambos os métodos utilizam o princípio da difusão para remoção dos lipídeos. Dentre os solventes, ou mistura destes, que podem ser empregados na extração, o etanol apresenta alta eficiência de extração, mas diversos contaminantes polares podem ser extraídos, tais como, sais, aminoácidos, açúcares, pigmentos e proteínas hidrofóbicas. ${ }^{75}$ De forma geral, após a extração são obtidos os lipídeos totais, que compreendem ácidos graxos, hidrocarbonetos, esteroides, acilgliceróis, pigmentos e os glico- e fosfolipídeos. Os lipídeos neutros, que são a fração conversível em biodiesel, são obtidos pela redissolução dos lipídeos totais em hexano, seguida da filtração em carvão ativado para remoção de pigmentos. ${ }^{74}$ Após a eliminação do solvente por evaporação, a massa dos lipídeos neutros é então determinada.

Têm sido realizados estudos com o emprego de extração assistida por ultrassom ou micro-ondas, buscando-se o máximo de remoção dos lipídeos. ${ }^{76}$ As ondas são aplicadas como método de rompimento das células, promovendo um maior contato do seu conteúdo interno com o solvente extrator. Balasubramanian e colaboradores ${ }^{73}$ realizaram comparações entre extrações utilizando hexano como solvente extrator, com e sem irradiação de micro-ondas. Segundo os autores, a extração assistida por micro-ondas possibilitou uma maior recuperação de lipídeos, com uma maior proporção de ácidos graxos poli-insaturados. Foram também realizadas comparações entre métodos de rompimento celular, ${ }^{77}$ incluindo, além de micro-ondas e ultrassom, a moagem com nitrogênio líquido e lise enzimática. Os resultados apontaram uma melhor eficiência para a moagem com nitrogênio, seguida da lise enzimática. Uma avaliação quanto à viabilidade econômica deve, contudo, ser realizada, principalmente no que diz respeito à obtenção das enzimas.

Estimativas mais rápidas para quantificação de lipídeos neutros intracelulares in vivo podem ser obtidas por citometria em fluxo, utilizando o corante vermelho do Nilo. ${ }^{78}$ Esta técnica baseia-se na medida da fluorescência do corante dissolvido em lipídeos neutros e da fluorescência da clorofila, com picos de emissão em 570 e 675 $\mathrm{nm}$, respectivamente. Por se tratar de um método rápido e menos laborioso, tem sido muito empregado para seleção de espécies de algas de alta produtividade em triacilgliceróis. ${ }^{79}$

A avaliação dos triacilgliceróis quanto à sua composição em ácidos graxos é de fundamental importância, dada a influência destes sobre propriedades do biodiesel como: a viscosidade cinemática, a massa específica, o ponto de entupimento de filtro a frio e a estabilidade oxidativa. A composição em ácidos graxos varia com a espécie da microalga, podendo diferir no tamanho da cadeia carbônica e/ou na presença e na quantidade de insaturações. Os ácidos graxos mais comuns possuem de 16 a 18 átomos de carbono na cadeia da carboxila. ${ }^{80}$ Usualmente, a caracterização de óleos e gorduras quanto aos ácidos graxos é realizada por cromatografia a gás (CG) com detecção por ionização com chama. $\mathrm{Na}$ análise, tanto os acilgliceróis quanto os ácidos graxos livres são previamente derivatizados por metanólise a alquilésteres mais voláteis, resultando em picos com excelente perfil e resolução. Usualmente, a metanólise é realizada na presença de catalisadores ácidos como $\mathrm{HCl}, \mathrm{H}_{2} \mathrm{SO}_{4}$ e $\mathrm{BF}_{3}$. Catalisadores básicos podem ser empregados, propiciando um menor tempo de reação, contudo, ao contrário dos catalisadores ácidos, estes são desativados se água e ácidos graxos livres estiverem presentes em quantidades apreciáveis. ${ }^{81}$

Na caracterização, comumente são usadas colunas capilares polares ${ }^{82}$ que promovem uma maior resolução dos ésteres. Como padrões internos, ésteres metílicos de ácidos graxos de cadeia ímpar são muito empregados pelo fato de serem raros, evitando-se assim sobreposição de picos. Seguindo este raciocínio, o método cromatográfico EN ISO 14103, recomendado pela Resolução nº 14 de 2012 da ANP, utiliza o heptadecanoato de metila como padrão interno para determinação do teor de ésteres em biodiesel. Vários trabalhos, no entanto, apontam a presença de ácidos de cadeia ímpar em óleos de microalgas, a exemplo dos C11:0, C13:0, C15:0, C15:1, C17:0 e C17:1. ${ }^{83}$ Exemplos da caracterização de óleos de microalgas são apresentados na Tabela 4. Se o heptadecanoato de metila estiver presente no biodiesel e dependendo da sua concentração, o teor de ésteres poderá ser subestimado. ${ }^{84}$ É prudente, portanto, realizar antecipadamente uma análise qualitativa para que se possa escolher um padrão interno adequado.

Tabela 4. Teores de ácidos graxos em óleos de diferentes microalgas

\begin{tabular}{|c|c|c|c|c|}
\hline $\begin{array}{l}\text { Ácidos } \\
\text { graxos }\end{array}$ & $\begin{array}{c}\text { Spirulina } \\
\text { platensis-1 }\end{array}$ & Achnanthes sp. & S. nidulans & $\begin{array}{c}\text { Dunaliella } \\
\text { salina } \\
\text { (fração neutra) }\end{array}$ \\
\hline $\mathrm{C} 8: 0$ & 3,72 & --- & --- & --- \\
\hline C11:0 & 1,06 & --- & --- & --- \\
\hline C11:1 & 1,65 & --- & --- & --- \\
\hline C12:0 & 0,84 & --- & --- & --- \\
\hline C13:0 & 0,72 & --- & --- & 4,27 \\
\hline C14:0 & nd & 7,0 & --- & 1,48 \\
\hline C15:0 & 0,70 & 1,5 & 0,08 & --- \\
\hline C15:1 & 1,26 & --- & --- & --- \\
\hline C16:0 & 42,30 & 30,4 & 0,73 & 24,12 \\
\hline C16:1 & 1,00 & 45,0 & 36,04 & 5,73 \\
\hline C16:2 & 2,43 & --- & --- & 0,86 \\
\hline $\mathrm{C} 17: 0$ & 0,45 & --- & 8,18 & --- \\
\hline $\mathrm{C} 17: 1$ & nd & --- & 2,73 & 1,11 \\
\hline C18:0 & 0,95 & 0,6 & 0,78 & 13,26 \\
\hline C18:1 & 1,97 & 0,94 & 16,9 & 7,17 \\
\hline C18:2 & 16,18 & 1,0 & 3,53 & 8,60 \\
\hline C18:3 & 20,06 & 0,5 & 17,82 & 30,33 \\
\hline $\mathrm{C} 20: 2$ & 0,94 & --- & 7,64 & --- \\
\hline C20:5 & --- & 12,3 & 0,10 & --- \\
\hline $\mathrm{C} 24: 0$ & 0,90 & 0,8 & 0,09 & --- \\
\hline Referências & 85 & 86 & 87 & 88 \\
\hline
\end{tabular}

Outra restrição está relacionada com a quantidade de carbonos ativos presentes na molécula. Como o carbono da carboxila do éster não contribui para a resposta no FID, a quantidade relativa de carbonos ativos diminui à medida que reduz a massa molar do éster, resultando em respostas diferenciadas para os ésteres. ${ }^{89}$ Neste caso, 
fatores de correção teóricos, propostos por Ackman e Sipos, ${ }^{90}$ podem ser utilizados para correção das áreas dos picos no cromatograma, contudo esses só são válidos quando se utiliza injeção on-column. Diferenças acentuadas poderão ser observadas quando se utiliza injeção do tipo split para amostras de óleos (ou biodiesel), que apresentem quantidades significativas de ácidos graxos com cadeias menores que $\mathrm{C} 14$ e maiores que C24. ${ }^{89}$ Misturas de ácidos graxos, cujas massas molares variam enormemente, resultarão numa ampla faixa de volatilidade e, consequentemente, ocorrerá discriminação de compostos durante a injeção split, acarretando na introdução de uma fração não representativa da amostra na coluna cromatográfica.

A cromatografia a gás com detecção por espectrometria de massa é frequentemente empregada na caracterização de óleos e gorduras. ${ }^{91} \mathrm{~A}$ identificação dos ácidos graxos é realizada tanto pela comparação com os tempos de retenção dos alquil ésteres, como pela fragmentação no espectro de massa. Para este fim, misturas padrões de ésteres metílicos, comercialmente disponíveis, são amplamente empregadas. Estes padrões de ésteres também são utilizados para obtenção de fatores de respostas experimentais a serem empregados em análises quantitativas. ${ }^{92}$

\section{PRODUÇÃO DO BIODIESEL}

A produção de biodiesel de óleo de microalgas, a priori, envolve as etapas de extração dos lipídeos da biomassa microalgal, a remoção do excesso de solvente e a produção de biodiesel por transesterificação catalisada, dependendo das características físico-químicas do óleo, por bases ou ácidos ou enzimas, usando catalisadores homogêneos ou heterogêneos. ${ }^{93}$ Outras alternativas podem ser a esterificação, esterificação seguida de transesterificação, hidroesterificação ou, ainda, a realização da extração do óleo e transesterificação em uma única etapa, também conhecida como transesterificação in situ. Estes processos podem ser conduzidos ainda com a aplicação de ultrassom ou micro-ondas. ${ }^{94}$

A transesterificação também pode ser conduzida na ausência de catalisador, usando condições supercríticas de álcool. Este processo, no entanto, apesar de conduzir a um menor tempo de reação e reduzir significativamente os processos de separação e purificação dos produtos, requer altas temperaturas e pressão, onerando em termos materiais e energéticos. ${ }^{95}$

Miao e $\mathrm{Wu},{ }^{35}$ ao utilizar óleo de microalgas, observaram que catalisadores alcalinos convencionais não eram adequados para a sua transesterificação, provavelmente devido ao elevado índice de acidez do óleo (8,97 mg KOH g $\left.{ }^{-1}\right)$, que conduz a reações secundárias, como a saponificação. Os autores realizaram experimentos para determinar as condições ideais para a transesterificação ácida de óleo de microalgas. Utilizou-se o óleo da microalga Chlorella protothecoides, obtida em cultivo heterotrófico. O rendimento e a densidade do biodiesel foram avaliados, sob diferentes temperaturas e quantidades de catalisador (com base no peso de óleo). Economicamente, a combinação do processo com $100 \%$ de catalisador quanto à massa do óleo e temperatura de $30^{\circ} \mathrm{C}$ foi a condição mais favorável, pois neste caso o custo de produção foi inferior à alternativa de uso do catalisador $\mathrm{H}_{2} \mathrm{SO}_{4}$ em alta temperatura por um longo tempo. Foram estudados ainda os efeitos da variação na razão molar metanol/óleo sobre o rendimento e a densidade do biodiesel. Foram obtidos rendimentos de 68 e $63 \%$ em biodiesel na razão molar 45:1 e 56:1, respectivamente.

A mesma espécie, Chlorella protothecoides, foi estudada por $\mathrm{Xu}$ e colaboradores ${ }^{36}$ para a produção de biodiesel através da reação de transesterificação. Neste experimento, aplicou-se a técnica de controle metabólico através do crescimento heterotrófico, sendo alcançado um teor de lipídeo bruto de 55,2\% na biomassa algal. As células foram colhidas por centrifugação e passaram por secagem a frio. A extração do óleo foi realizada com solvente n-hexano e o biodiesel foi obtido por transesterificação ácida. Foram determinadas as seguintes propriedades do biodiesel obtido: densidade, viscosidade, ponto de fulgor, ponto de entupimento de filtro a frio, índice de acidez e poder calorífico. Estes resultados são mostrados e comparados com a Resolução vigente da ANP (Tabela 5).

Tabela 5. Comparação das propriedades do biodiesel de óleo de microalgas obtido por Xu e colaboradores ${ }^{36}$ com os parâmetros da Resolução ANP para o biodiesel

\begin{tabular}{|c|c|c|}
\hline Propriedades & $\begin{array}{c}\text { Biodiesel de óleo } \\
\text { de microalgas }\end{array}$ & $\begin{array}{c}\text { Resolução ANP } \\
14 / 2012\end{array}$ \\
\hline Massa específica a $20^{\circ} \mathrm{C}\left(\mathrm{kg} \mathrm{m}^{-3}\right)$ & 0,864 & $850-900$ \\
\hline Viscosidade cinemática a $40^{\circ} \mathrm{C}\left(\mathrm{mm}^{2} \mathrm{~s}^{-1}\right)$ & 5,2 & $3,0-6,0$ \\
\hline Ponto de fulgor $\left(\mathrm{C}^{\circ}\right)$ & 115 & Min.100 \\
\hline 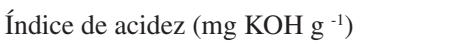 & 0,374 & Max. 0,50 \\
\hline Poder calorífico ( $\left.\mathrm{MJ} \mathrm{kg}^{-1}\right)$ & 41 & - \\
\hline
\end{tabular}

Buscando superar as limitações da etapa de extração do óleo de células de microalgas, Johnson e Wen ${ }^{96}$ avaliaram o potencial de produção de biodiesel a partir da microalga Schizochytrium limacinum através da transesterificação in situ da biomassa algal, utilizando como solventes clorofórmio, hexano ou éter de petróleo. Produziuse biodiesel através de dois métodos: extração do óleo das células de microalgas, seguida por transesterificação, e transesterificação direta (in situ) da biomassa microalgal. Os autores obtiveram o maior rendimento em biodiesel, quando utilizaram a transesterificação direta. Os principais ésteres metílicos de ácidos graxos contidos no biodiesel foram ésteres de ácido mirístico (C14:0), ácido palmítico (C16:0), ácido docosapentaenoico (C22:5) e ácido docosa-hexaenoico (C22:6). O biodiesel obtido por este processo foi avaliado quanto à sua qualidade. Os parâmetros glicerol livre, glicerol total, índice de acidez, corrosividade ao cobre, ponto de fulgor, material particulado, viscosidade e sabão obedeceram aos limites estabelecidos pela norma da American Society for Testing and Materials (ASTM); no entanto, os valores para água e sedimentos e o teor de enxofre não ficaram enquadrados nesta norma.

Vargas e colaboradores ${ }^{97}$ realizaram a metanólise in situ usando as espécies Nannochloropsis oculata a $80^{\circ} \mathrm{C}$ por $2 \mathrm{~h}$, e concluíram que o processo apresenta um balanço energético de 1,17, comparativamente maior que o balanço energético obtido para o processo de produção de biodiesel de soja e de girassol, que apresentam valores de 1,06 e 1,12 , respectivamente.

Whahlen e colaboradores ${ }^{98}$ avaliaram a influência do teor de água residual na biomassa microalgal na cinética da transesterificação direta e, conforme se esperava, constataram que quanto maior o teor de água, menor o rendimento em ésteres, ressaltando a importância do processo de secagem.

A tecnologia de transesterificação in situ em duas etapas para a produção de biodiesel também foi avaliada por $\mathrm{Xu}$ e Mi, ${ }^{99}$ a partir da Spirulina (biomassa seca), usando-se um cossolvente. Foram avaliados os seguintes cossolventes: tolueno, diclorometano e dietiléter, bem como as seguintes combinações: éter de petróleo:tolueno, tolueno:metanol e diclorometano:metanol. Dentre as opções avaliadas, o sistema tolueno:metanol na proporção 2:1 levou a uma maior eficiência, com rendimento em biodiesel de $76 \%$ no primeiro ciclo de transesterificação in situ e $10 \%$ no segundo ciclo. Convém salientar que as condições utilizadas pelos autores (temperatura ambiente, 1 min de agitação e 1 h de reação sem agitação) caracterizam este processo como pouco demandante em energia quando comparado com o processo de transesterificação homogêneo alcalino. 
Como já mencionado anteriormente, a produção de biodiesel também pode ser conduzida com o uso de catalisadores heterogêneos. Esta tecnologia possibilita a redução significativa das etapas de purificação dos produtos (biodiesel e glicerina), uma vez que permite, ao contrário do processo que usa catalisadores homogêneos, a fácil separação dos produtos e ainda a reutilização do catalisador sólido ao longo de sua vida útil, com consequente redução da geração de efluentes. Nos últimos anos, vários autores avaliaram sólidos como potenciais catalisadores heterogêneos para a produção de biodiesel e foram publicados excelentes artigos de revisão. ${ }^{100}$

Um processo contínuo que usa catalisador heterogêneo e diferentes espécies de microalgas foi estudado por Brian e colaboradores. ${ }^{101}$ Este processo, comercialmente conhecido como processo Mcgyan ${ }^{\circledR}$, utiliza microesferas de óxido de titânio poroso nas condições supercríticas do metanol e permite a condução simultânea das reações de transesterificação dos triacilglicerídeos e da esterificação dos ácidos graxos livres em ésteres metílicos com eficiência de até $85 \%$.

Li e colaboradores ${ }^{37}$ realizaram a extração e transesterificação simultânea do óleo da microalga Nannochloropsis sp. por 4 h a 65 ${ }^{\circ} \mathrm{C}$, em um extrator Soxhlet modificado para possibilitar a colocação do catalisador heterogêneo básico $\mathrm{Mg}-\mathrm{Zr}$, preparado por coprecipitação, em um leito fixo. A mistura metanol-diclorometano foi usada no processo. Para efeito de comparação, os autores realizaram o processo em duas etapas, ou seja, extração por $4 \mathrm{~h}$ a $65^{\circ} \mathrm{C}$, seguida pela remoção do excesso de solvente. Depois, o óleo extraído foi transesterificado por $4 \mathrm{~h}$ a $65^{\circ} \mathrm{C}$, com metanol sob refluxo e $10 \%$ em massa de catalisador relativo à biomassa microalgal seca. $\mathrm{O}$ processo em uma etapa resultou num maior rendimento em éster do que o processo em duas etapas e, segundo os autores, ainda possui a vantagem adicional de consumir menos energia, com consequente redução dos custos totais.

Ésteres metílicos obtidos a partir da transesterificação (razão metanol:óleo 6:1, tempo de reação de $1 \mathrm{~h}$, temperatura de $60^{\circ} \mathrm{C}$ e $1 \%$ $\mathrm{m} / \mathrm{m}$ de $\mathrm{KOH}$ ) do óleo da microalga $C$. protothecoides apresentaram na composição aproxidamente 90,75 ésteres de insaturados e, consequentemente, um excelente valor de temperatura de entupimento a frio $\left(-13{ }^{\circ} \mathrm{C}\right)$ e uma baixa estabilidade oxidativa $(4,5 \mathrm{~h}) .{ }^{102}$

\section{ASPECTOS AMBIENTAIS}

O desempenho ambiental dos biocombustíveis e seus aspectos técnico-econômicos têm sido considerados de forma crescente como um elemento essencial no desenvolvimento de novos processos e produtos nesta área. Sua importância está diretamente relacionada à necessidade de identificar aspectos críticos e as melhores alternativas tecnológicas do ponto de vista ambiental, bem como avaliar se, e em que medida, os impactos ambientais associados aos biocombustíveis são menores do que os impactos causados pelos seus concorrentes de origem fóssil.

Vários aspectos ambientais têm sido propostos nos últimos anos para avaliar o desempenho ambiental dos biocombustíveis, com destaque para: o balanço energético (input e output), o consumo de recursos naturais não renováveis, o consumo de água, o impacto sobre os solos e a biodiversidade, a emissão de gases provocadores do efeito estufa (GEE) e a emissão de diversos outros poluentes para a atmosfera, o solo e a água. ${ }^{103}$

Dentre as metodologias utilizadas para avaliação do desempenho ambiental de processos e produtos tem se destacado, nos últimos anos, a avaliação do ciclo de vida (ACV), uma ferramenta especificada pelas normas ISO 14040 e 14044 . A ACV é uma ferramenta de gestão ambiental que se enquadra no âmbito da ecologia industrial, sendo definida como uma técnica quantitativa para determinar os potenciais impactos ambientais associados a um produto ou serviço, compreendendo etapas que vão desde a extração de matéria-prima da natureza, que entra no sistema, à disposição final de resíduos. Esta quantificação é realizada a partir de um inventário das intervenções ambientais relevantes em todo o ciclo de vida desse produto ou serviço. Em inglês usa-se a expressão cradle-to-grave, do berço ao túmulo, para reforçar a intenção de uma abordagem completa e sistêmica. ${ }^{104}$

No caso específico de tecnologias novas em processo de desenvolvimento, como os biocombustíveis produzidos a partir de microalgas, a ACV possibilita a identificação de gargalos tecnológicos e oferece um suporte no desenvolvimento de produtos, processos e serviços que apresentem características eficientes do ponto de vista energético e favoráveis do ponto de vista ambiental, caracterizando o que tem sido denominado internacionalmente por ecodesign (consiste na redução dos impactos ambientais de todo o ciclo de vida através de melhorias na concepção de produtos).

Uma revisão dos estudos de ACV para a produção do biodiesel ${ }^{105}$ desde a década de 90 aponta convergências quanto ao balanço energético favorável, apresentando valores na faixa de 1,5 a 5,0 (uma unidade de energia investida no sistema produz até cinco unidades de energia), tendo sua variação associada às diferentes matérias-primas, intensidades no uso de insumos agroquímicos e cenários de coprodutos.

Apesar da grande variação nos resultados quanto ao potencial do biodiesel na redução da emissão de gases provocadores do efeito estufa (GEE), um grande número de estudos indica reduções entre 40 e $85 \%$, quando se utiliza o biodiesel em substituição ao diesel fóssil. Por outro lado, alguns estudos são desfavoráveis ao biodiesel, quando se consideram as emissões diretas e indiretas da mudança no uso da terra. ${ }^{106}$ Com relação às emissões para a atmosfera, água e solo destacam-se as emissões de gases acidificantes e eutrofizantes. Nas duas categorias, a maioria dos estudos aponta uma desvantagem para o biodiesel, quando comparado ao diesel fóssil. ${ }^{107}$

O desenvolvimento tecnológico da produção de matérias-primas para o biodiesel tem-se direcionado para aquelas que não concorrem com usos não energéticos e que possuem maior eficiência energética e compatibilidade ambiental no uso dos recursos naturais. As microalgas têm sido apontadas como alternativas às oleaginosas de cultivo terrestre, como matéria-prima para a produção de biodiesel, especialmente devido à sua elevada produtividade por unidade de área e por não apresentarem concorrência no uso do solo para a produção de alimentos. ${ }^{108}$ Por outro lado, a elevada demanda por energia, fertilizantes e $\mathrm{CO}_{2}$ pode limitar as vantagens comparativas desta alternativa. ${ }^{109}$

Balanços de energia e de GEE realizados por Khoo e colaboradores ${ }^{110}$ para diferentes cenários de produção de biodiesel, utilizando o sistema integrado fotobiorreator-raceway para o cultivo de microalgas, em Cingapura, obtiveram resultados desfavoráveis do ponto de vista energético, com uma demanda total de energia de 4,44 MJ por MJ de biodiesel, sendo $13 \%$ desta energia para a produção de biomassa, $85 \%$ para a extração de lipídeos e $2 \%$ para a produção de biodiesel. Os estudos de sensibilidade apontaram que no melhor cenário, com otimização do uso da energia e conteúdo de lipídeos ( $45 \%$ peso seco) na biomassa algal, pode-se alcançar uma redução no consumo de energia para 1,3 MJ por MJ de biodiesel, mas que ainda é desvantajosa. Em concordância, Jorquera e colaboradores ${ }^{111}$ encontraram valores de consumo de energia elevados e, portanto, desfavoráveis para a produção de biomassa algal em tanques do tipo raceway e fotobiorreatores tubulares e de placas planas, ressaltando a necessidade de aumentar o conteúdo lipídico da biomassa algal para aumentar a eficiência energética do processo.

Lardon e colaboradores, ${ }^{112}$ utilizando uma ACV comparativa, estudaram o balanço energético e os impactos ambientais de cenários para a produção de biodiesel a partir de microalgas, baseados 
em resultados de laboratório, extrapolados para instalações de porte comercial. A melhor alternativa, o cultivo com déficit de nitrogênio e a colheita úmida, foi então comparada ao ciclo de vida do biodiesel de diferentes oleaginosas terrestres e do óleo diesel. Comparativamente, o cenário de microalgas demonstrou ser a pior opção nas categorias ambientais: radiação ionizante, oxidação fotoquímica e toxicidade marinha, e a segunda pior na categoria esgotamento de recursos naturais abióticos. Por outro lado, foi favorável nas categorias de impacto: eutrofização, mudança no uso da terra, acidificação, toxicidade humana e destruição da camada de ozônio.

Lardon e colaboradores ${ }^{112}$ concluíram que, nas condições propostas, o biodiesel de microalgas ainda não é uma alternativa ambientalmente favorável, mas com possibilidades de melhorias para reduzir a maior parte dos impactos identificados no estudo. Os seguintes aspectos são apontados como relevantes para a otimização: microalgas que mantenham altos teores de lipídeos com taxa de crescimento sustentado, métodos de extração energeticamente eficientes, recuperação de energia e de nutrientes dos coprodutos e resíduos do ciclo de vida do biodiesel, dentro do conceito de biorrefinarias integradas, visando o melhor aproveitamento dos recursos naturais e energéticos, com a minimização de perdas e de geração de resíduos. Resultados obtidos por diversos autores corroboram os resultados obtidos por Lardon e colaboradores, com destaque para Collet e colaboradores ${ }^{103}$ e Xu e colaboradores, ${ }^{113}$ que apontam a importância da utilização de nutrientes, água e $\mathrm{CO}_{2}$ residuais de outros processos.

Campbell e colaboradores ${ }^{114}$ realizaram um estudo de emissões de GEE, com base na ACV, comparando o biodiesel de microalgas cultivadas em tanques abertos com o biodiesel de canola e o diesel de baixo teor em enxofre. Os resultados indicaram vantagens para o biodiesel de microalgas para todos os cenários de fornecimento de $\mathrm{CO}_{2}$, em comparação com os outros dois combustíveis.

Harto e colaboradores ${ }^{115}$ realizaram ACV comparativa para avaliar o consumo de água de diferentes biocombustíveis propostos como alternativa para redução das emissões de gases estufa no setor de transporte. Os resultados indicaram um elevado consumo de água para a maioria dos biocombustíveis, com destaque para os produzidos a partir de cultivos agrícolas terrestres e de microalgas produzidas em sistemas abertos, em regiões semiáridas. Os autores ressaltam que a adoção em larga escala dessas tecnologias pode ter um impacto significativo sobre a demanda global de água.

Delrue e colaboradores ${ }^{116}$ avaliaram comparativamente a influência de diferentes parâmetros sobre o desempenho energético (razão de energia líquida), ambiental (pegadas de carbono e de água) e econômico (custos) da produção de biodiesel de microalgas. $\mathrm{O}$ cultivo em tanques abertos foi a opção de menor custo e emissão de GEE, enquanto os fotobiorreatores se destacaram pelo baixo consumo de água. $\mathrm{O}$ balanço de energia, porém, foi equivalente nas duas alternativas. Com relação aos demais processos (secagem, extração e aproveitamento de coprodutos) destacaram-se a secagem em leitos, comparada com o uso de centrífugas, filtro prensa e secador solar; o uso do DME (éter dimetílico) em comparação ao uso do hexano e, a biodigestão, comparada à gaseificação.

Conclui-se que os principais aspectos ambientais favoráveis à produção de biodiesel a partir de biomassa algal são o seu elevado potencial fotossintético e, por consequência, sua elevada capacidade de produção de bioenergia por unidade de área, em comparação com outras fontes de biomassa. Por outro lado, os principais desafios encontram-se associados à busca de sistemas otimizados para elevar a produção de biomassa e o conteúdo de lipídeos, o desenvolvimento de tecnologias de colheita e secagem da biomassa algal energeticamente eficientes, aproveitando calor residual e/ou excedente de outros processos produtivos. A integração com outros processos produtivos deve considerar aspectos sinérgicos, como o aproveitamento de nutrientes e de $\mathrm{CO}_{2}$, resultando na redução da demanda energética e na mitigação dos impactos ambientais.

\section{CONSIDERAÇÕES FINAIS}

Apesar do forte interesse dos atores econômicos e científicos, até agora não se tem conhecimento da existência de nenhuma instalação industrial para a produção de biodiesel a partir de microalgas. No entanto, há iniciativas importantes no sentido de alcançar a viabilidade econômica e ambiental, o que constitui um dos principais desafios para a implementação em larga escala de biocombustíveis a partir de microalgas. Os custos de produção variam significativamente com a escala e o sistema de produção. As etapas de separação das microalgas e de extração dos óleos são onerosas devido à alta demanda por energia e os custos de capital envolvidos. ${ }^{117}$

Há pesquisas em andamento em vários países, visando o desenvolvimento de sistemas de produção de biodiesel a partir de microalgas a custos viáveis. Pesquisadores chineses do Departamento de Ciências Biológicas e Biotecnologia da Tsinghua University, em Pequim, citados diversas vezes nesta revisão, têm estudado a produção de biodiesel a partir da espécie Chlorella protothecoides, em crescimento heterotrófico, utilizando fontes de carbono orgânico mais baratas em substituição à glicose, e em todos estes trabalhos os resultados se mostraram promissores. ${ }^{118}$

Na mesma linha de estudos, pesquisadores da Virginia Polytechnic Institute and State University (EUA) inovaram utilizando glicerol bruto derivado de usinas de biodiesel como fonte de carbono de baixo custo para o cultivo heterotrófico da espécie Schizochytrium limacinum e, produzindo biodiesel a partir desta microalga através de uma transesterificação direta (ou in situ) da biomassa algal. ${ }^{118}$ No processo de baixo custo, produziu-se biodiesel de qualidade, com bom rendimento e, ainda, fechando um ciclo ao possibilitar o uso do principal coproduto da indústria de biodiesel.

Acerca dos aspectos ambientais, os diversos autores recomendam que, para a produção em grande escala, devem ser consideradas as seguintes melhorias: (i) a escolha das espécies de microalgas que mantenham altos teores de lipídeos com taxa de crescimento sustentado, (ii) a instalação de métodos de extração energeticamente eficientes e (iii) a recuperação de materiais, energia e nutrientes contidos nos subprodutos, como parte do conceito de biorrefinarias integradas. Estudos de análises de ciclo de vida tomando como base as tecnologias atuais mostram limitações quanto ao balanço energético e mitigação dos gases do efeito estufa. ${ }^{13}$

A Ficologia Aplicada progrediu muito nos últimos anos, mas grandes problemas e incertezas permanecem sem resposta. A razão mais importante, claramente notada em eventos e reuniões desta área, é o esforço individual isolado, com poucas ações cruzadas, troca de know-how e projetos conjuntos. O interesse na bioenergia e o potencial das microalgas como fonte de combustível pode e deve proporcionar uma oportunidade para um esforço multi-institucional comum.

No Brasil, as iniciativas referentes ao tema vêm se multiplicando. No Congresso da Rede Brasileira de Tecnologia de Biodiesel houve um expressivo aumento no número de publicações: do $1^{\circ}$ Congresso realizado em 2006 (uma única publicação ${ }^{119}$ ) para o $5^{\circ}$ Congresso (34 publicações ${ }^{120}$ ) realizado em 2012. Além da evolução do número de publicações, foram abordados nesse último congresso vários temas envolvendo o uso de microalgas para a produção de biodiesel (matéria-prima, produção, caracterização e políticas). Temos pesquisadores envolvidos nesta área de norte a sul, desenvolvendo projetos para a produção de biodiesel. São raras, porém, as produções comerciais de biomassa seca. Por outro lado, é crescente o investimento do governo nestas pesquisas, incrementando 
a capacitação de vários grupos de pesquisa, o que tem permitido avanços que possibilitarão a expansão da produção de lipídeos em grande escala nos próximos 10-15 anos. ${ }^{111}$

\section{REFERENCIAS}

1. http://www.eia.gov/forecasts/aeo/pdf/0383(2012).pdf, acessada em Janeiro 2013.

2. http://www.opec.org, acessada em Janeiro 2013.

3. Beatriz, A.; Araujo, Y. J. K.; de Lima, D. P.; Quim. Nova 2011, 34, 306.

4. http://www.mme.gov.br/spg/menu/publicacoes.html, acessada em Janeiro 2013.

5. Chisti, Y.; Biotechnol. Adv. 2007, 25, 294.

6. Ehimen, E. A.; Sun, Z. F.; Carrington, C. G.; Birch, E. J.; Eaton-Rye, J. J.; Appl. Energy 2011, 88, 3454; Vargas, J. V. C.; Mariano, A. B.; Satyanarayana, K. G.; Int. J. Energy Res. 2011, 35, 291.

7. Schenk, P. M.; Thomas-Hall, S. R.; Stephens, E.; Marx, U. C.; Mussgnug, J. H.; Posten, C.; Kruse, O.; Hankamer, B.; Bioenerg. Res. 2008, 1, 20; Malcata, F. X.; Guedes, A. C.; Amaro, H. M.; Appl. Energy 2011, 88, 3402; Mutanda, T.; Ramesh, D.; Karthikeyan, S.; Kumari, S.; Anandraj, A.; Bux, F.; Bioresour. Technol. 2011, 102,57; Almarales, A.; Chenard, G.; Abdala, R.; Gomes, D. A.; Reyes,Y.; Tapanes, N. O.; Nat. Sci. 2012, 4, 204.

8. Melis, A.; Happe, T,; Plant Physiol. 2001, 127, 740; Kosourov, S.; Seibert, M.; Ghirardi, M. L.; Plant Cell Physiol. 2003, 44, 146; Amutha, K. B.; Murugesan, A. G.; Bioresour. Technol. 2011, 102, 194.

9. Ruan, R.; Chen, P.; Liu, Y.; Lin, X.; Wang, C.; Chen, Q.; Wan, Y.; Wang, X.; Li, Y.; Du, Z.; Bioresour. Technol. 2011, 102, 4890.

10. Harun, R.; Jason, W. S. Y.; Cherrihgton, T.; Danquah, M. K.; Appl. Energy 2011, 88, 3464.

11. Derner, R. B.; Ohse, S.; Villela, M.; Carvalho, S. M.; Fett, R.; Ciência Rural 2006, 36, 1959.

12. http://www.futureenergyevents.com/algae/whitepaper, acessada em Janeiro 2013; http://www.emerging-markets.com, acessada em Janeiro 2013.

13. Scott, S. A.; Davey, M. P.; Dennis, J. S.; Horst, I.; Howe, C. J.; LeaSmith, D. J.; Smith, A. G.; Curr. Opin. Biotechnol. 2010, 21, 277.

14. Coutinho, P.; Bomtempo, J. V.; Quim. Nova 2011, 34, 910; Delrue, F.; Setier, P. A.; Sahut, C.; Cournac, L.; Roubaud A.; Peltier, G.; Froment, A. K.; Bioresour. Technol. 2012, 111, 191.

15. http://www.nrel.gov/docs/legosti/fy98/24190.pdf, acessada em Janeiro 2013.

16. Huntley, M. E.; Redalje, D. G.; Mitig. Adapt. Strategies Glob. Change 2006, 12, 573.

17. Menezes, R.S., comunicação pessoal.

18. Gouveia, L.; Oliveira, A. C.; J. Ind. Microbiol. Biotechnol. 2009, 36, 269; Gong, Y.; Jiang, M.; Biotechnol. Lett. 2011, 33, 1269.

19. Schenk, P. M.; Thomas-Hall, S. R.; Stephens, E.; Marx, U. C.; Mussgnug, J. H.; Posten, C.; Kruse, O.; Hankamer, B.; Bioenerg. Res. 2008, $1,20$.

20. Yamaberi, K.; Takagi, M.; Yoshida, T.; J. Mar. Biotechnol. 1998, 6, 44.

21. Jiang, L.; Luo, S.; Fan, X.; Yang, Z.; Guo, R.; Appl. Energy 2011, 88, 3336; Ohse, S.; Derner, R. B.; Ozório, R. A.; Braga, M. V. C.; Cunha, P.; Lamarca, C. P.; dos Santos, M. E.; Biotemas 2008, $21,7$.

22. Malcata, F. X.; Guedes, A. C.; Amaro, H. M.; Appl. Energy 2011, 88, 3402; Ghasemi, Y.; Rasoul_Amini, S.; Naseri, A. T.; Montazeri_Najafabady, N.; Mobasher, M. A.; Dabbagh, F.; Appl. Biochem. Microbiol. 2012, 48, 126.

23. Grobbelaar, J. U. Em Handbook of Microalgal Culture: Biotechnology and Applied Phycology; Richmond, A., ed.; Blackwell Science: Oxford, 2004, chap. 6.

24. Richmond, A. Em Handbook of Microalgal Mass Cultures; Richmond A., ed; CRC: Boca Raton, 1986.
25. Andersen, R. A., ed.; Algal culturing techniques; Elsevier Academic Press: China, 2005; Lourenço, S. O.; Cultivo de microalgas marinhas: Princípios e aplicações, Rima: São Carlos, 2006.

26. Moazami, N.; Ranjbar, R.; Ashori, A.; Tangestani, M.; Sheykhi N. A.; Biomass Bioenerg. 2011, 35, 1935.

27. Liang, Y.; Sarkany, N.; Cui, Y.; Biotechnol. Lett. 2009, 31, 1043; Liu, X.; Duan, S.; Li, A.; Xu, N.; Cai, Z.; Hu, Z.; J. Appl. Phycol. 2009, 21 , 239; Cheirsilp, B.; Torpee, S.; Bioresour. Technol. 2012, 110, 510.

28. Huang, G.; Chen, F.; Wei, D.; Zhang, X.; Chen, G.; Appl. Energy 2010, 87,38 .

29. Lohrey, C.; Kochergin, V.; Bioresour. Technol. 2012, 108, 76.

30. Ragni, M.; Airs, R. L.; Leonardos, N.; Geider, R. J.; J. Phycol. 2008, 44, 670.

31. García, M. C.; Sevilla, J. M. F.; Fernández, F. G. A.; Grima, E. M.; Camacho, F. G.; J. Appl. Phycol. 2000, 12, 239.

32. Gao, C.; Zhai, Y.; Ding, Y.; Wu, Q.; Appl. Energy 2010, 87, 756; Xiong, W.; Gao, C.; Yan, D.; Wu, C.; Wu, Q.; Bioresour. Technol. 2010, 101, 2287.

33. Cid, A.; Abalde, J.; J. Appl. Phycol. 1992, 4, 31.

34. Heredia-Arroyo, T.; Wei, W.; Hu, B.; Appl. Biochem. Biotechnol. 2010, 162, 1978.

35. Miao, X.; Wu, Q.; Bioresour. Technol. 2006, 97, 841.

36. Xu, H.; Miao, X.; Wu, Q.; J. Biotechnol. 2006, 126, 499.

37. Li, Y.; Lian, S.; Tong, D.; Song, R.; Yang, W.; Fan, Y.; Qing, R.; Hu, C.; Appl. Energy 2011, 88, 3313.

38. Liang, Y.; Sarkany, N.; Cui, Y.; Biotechnol. Lett. 2009, 31, 1043.

39. Endo, H.; Nakajima, K.; Chino, R.; Shirota, M.; Agricul. Biol. Chem. 1974, 38, 9 .

40. Ogawa, T.; Aiba, S.; Biotechnol. Bioeng. 1981, 23, 1121.

41. Ogbonna, J. C.; Masui, H.; Tanaka H.; J. Appl. Phycol. 1997, 9, 359.

42. Wu, L. F.; Chen, P. C.; Huang. A. P.; Lee, C. M.; Bioresour. Technol. 2012, 113, 14; Wanga, H.; Xiong, H.; Hui, Z.; Zeng, X.; Bioresour. Technol. 2012, 104, 215; Zhou, W.; Min, M.; Li, Y.; Hu, B.; Ma, X.; Cheng, Y.; Liu, Y.; Chen, P.; Ruan, R.; Bioresour. Technol. 2012, 110, 455.

43. Pyle, D. J.; Garcia, R. A.; Wen, Z. Y.; J. Agric. Food Chem. 2008, 56, 3933.

44. Xiong, W.; Gao, C.; Yan, D.; Wu, C.; Wu, Q.; Bioresour. Technol. 2010 , 101, 2287.

45. Moazami, N.; Ashori, A.; Ranjbar, R.; Tangestani, M.; Eghtesadi, R.; Nejad, S.; Biomass Bioenergy 2012, 39,449.

46. Mata, T. M.; Martins, A. A.; Caetano, N. S.; Renew. Sust. Energy Rev. 2010, 14, 217.

47. Belkin, S.; Boussiba, S.; Plant Cell Physiol. 1991, 32, 953.

48. Borowitzka, M. A.; Hallegraeff, G. M. Em Algae of Australia: introduction; McCarthy, P. M.; Orchard, A. E., eds.; Australian Biological Resources Study: Canberra, 2007, chap. 29.

49. Demirbas, A.; Energy Convers. Manage. 2010, 51, 2738.

50. Grobbelaar, J. U.; J. Appl. Phycol. 2009, 21, 489; Amin, S.; Energ. Convers. Manage. 2009, 50, 1834; Demirbas, A.; Energy Convers. Manage. 2010, 51, 2738.

51. Papazi, A.; Makridis, P.; Divanach, P.; J. Appl. Phycol. 2010, $22,349$.

52. Gudin, C.; Thepenier, C.; Adv. Biotechnol. Processes 1986, 6, 73; Grima, E. M.; Belarbia, E.-H.; Fernández, F. G. A.; Medina, A. R.; Chisti, Y.; Biotechnol. Adv. 2003, 20, 491.

53. Knuckey, R. M.; Brown, M. R.; Robert, R.; Frampton, D. M. F.; Aquacult. Eng. 2006, 35, 300.

54. Becker, E.; Microalgae biotechnology and microbiology, Cambridge University Press: Cambridge, 1995.

55. Rossignol, N.; Vandanjon, L.; Jaouen, O.; Quemeneur, F.; Aquacult. Eng. 1999, 20, 191; Frappart, M.; Massé, A.; Jaffrin, M. Y.; Pruvost, J.; Jaouen, P.; Desalination 2011, 265, 279.

56. Poelman, E.; De Pauw, N.; Jeurissen, B.; Resour. Conserv. Recy. 1997, 19, 1. 
57. Oh, H. M.; Lee, S. J.; Park, M. H.; Kim, H. S.; Kim, H. C.; Yoon, J. H.; Kwon, G.; Yoon, B. D.; Biotechnol. Lett. 2001, 23, 1229; Lee, A. K.; Lewis, D. M.; Ashman, P. J. ; J. Appl. Phycol. 2009, 21, 559.

58. Henderson, R.; Sharp, E.; Jarvis. P.; Parsons, S.; Jefferson, B.; Water Sci. Technol. 2006, 6, 31.

59. Wu, Z.; Zhu, Y.; Huang, W.; Zhang, C.; Li, T.; Zhang, Y.; Li, A.; Bioresour. Technol. 2012, 110, 496.

60. Lee, A. K.; Lewis, D. M.; Ashman, P. J.; J. Appl. Phycol. 2009, 21, 559.

61. Teixeira, C. M.; Kirsten, F. V.; Teixeira P. C.; J. Appl. Phycol. 2012, 1, doi:10.1007/s10811-011-9773-1.

62. Borges, L.; Moro'n-Villarreyes, J.; D’Oca, M. G. M.; Abreu, P. C.; Biomass Bioenerg. 2011, 35, 4449.

63. Uduman, N.; Qi, Y.; Danquah, M. K.; Hoadley. A. F. A.; Chem. Eng. J. 2010, 162, 935.

64. Halim, R.; Danquah, M. K.; Webley, P. A.; Biotechnol. Adv. 2012, 30, 709.

65. Alabi, A. O.; Tampier, M.; Bibeau, E.; Microalgae Technologies \& Process for Biofuels/ Bioenergy Production in British Columbia, Final Report, The British Columbia Innovation Council, 2009; Malcata, F. X.; Guedes, A. C.; Amaro, H. M.; Appl. Energy 2011, 88, 3402.

66. Hu, Q.; Sommerfeld, M.; Jarvis, E.; Ghirardi, M.; Posewitz, M.; Seibert, M.; Darzins, A.; Plant. J. 2008, 54, 621.

67. Greenwell, H. C.; Laurens, L. M. L.; Shields, R. J.; Lovitt, R. W.; Flynn, K. J.; J. R. Soc. Interface 2010, 7, 703.

68. Salley, S. O.; Ng, S.; Meng Chen, K. Y.; Garcia, M. E. D.; Abunasser, N.; Tang, H.; Appl. Energy 2011, 88, 3324; Herrera-Valencia, V. A.; Contreras-Pool, P. Y.; Lopez-Adrian, S. J.; Echeverría, S. P.; Pérez, L. F. B.; Curr. Microbiol. 2011, 63, 151.

69. Halim, R.; Gladman, B.; Danquah, M. K.; Webley, P. A.; Bioresour Technol. 2011, 102, 178.

70. Thana, P.; Machmudah, S.; Goto, M.; Sasaki, M.; Pavasant, P.; Shotipruk, A.; Bioresour. Technol. 2008, 99, 3110; Halim, R.; Gladman, B.; Danquah, M. K.; Webley, P. A.; Bioresour. Technol. 2011, 102, 178.

71. Fu, C. C.; Hung, T. C.; Chen, J. Y.; Su, C. H.; Wu, W. T.; Bioresour. Technol. 2010, 101, 8750.

72. Carrero, A.; Vicente, G.; Rodriguez, R.; Linares, M.; del Peso, G. L.; Catal. Today 2011, 167, 148.

73. Balasubramanian, S.; Allen, J. D.; Kanitkar, A.; Boldor, D.; Bioresour Technol. 2011, 102, 3396.

74. Bligh, E. G.; Dyer, W. J.; Can. J. Biochem. Physiol. 1959, 37, 911; Krohn, B. J.; McNeff, C. V.; Yan, B.; Nowlan D.; Bioresour. Technol. 2011, 102, 94; McNichol, J.; MacDougall, K. M.; Melanson, J. E.; McGinn, P. J.; Lipids 2012, 47,195.

75. Wiyarno, B.; Yunus, R.M.; Mel, M.; J. Applied Sci. 2011, 11, 3607.

76. Ranjan, A.; Patil, C.; Moholkar, V. S.; Ind. Eng. Chem. Res. 2010, 49, 2979.

77. Zheng, H.; Yin, J.; Gao, Z.; Huang, H.; Ji, X.; Dou, C.; Appl. Biochem. Biotechnol. 2011, 164, 1215.

78. Chen, W.; Zhang, C.; Song, L.; Sommerfeld, M.; Hu, Q.; J. Microbiol. Methods 2009, 77, 41; Hyka, P.; Lickova, S.; Přibyl, P.; Melzoch, K.; Kovar, K.; Biotechnol. Adv. 2013, 31, 2.

79. Montero, M. F.; Aristizábal, M.; Reina, G. G.; J. Appl. Phycol. 2011, 23, 1053.

80. Hu, Q.; Sommerfeld, M.; Jarvis, E.; Ghirardi, M.; Posewitz, M.; Seibert, M.; Darzins, A.; Plant J. 2008, 54, 621.

81. Carvalho, A. P.; Malacata, F. X.; J. Agric. Food Chem. 2005, 53, 5049.

82. Mohan, V.; Devi, M. P.; Mohana Krishna, G.; Amarnath, N.; Babu, M. L.; Sarma, P. N.; Bioresour. Technol. 2011, 102, 1109.

83. Kaur, S.; Sarkar, M.; Srivastava, R. B.; Hemanta, K.; Gogoi, H. K.; Kalita, M. C.; New Biotechnol. 2012, 29, 332.

84. Schober, S.; Seidl, I.; Mittelbach, M.; Eur. J. Lipid Sci. Technol. 2006, $108,309$.

85. Ötleô, S.; Pire, R.; J. AOAC Int. 2001, 84, 1708.
86. Doan, T. T. Y.; Sivaloganathan, B.; Obbard, J. P.; Biomass Bioenerg. 2011, 35, 2534.

87. Radmann, E. M.; Costa, J. A. V.; Quim. Nova 2008, 31, 1609.

88. Guzmán, H. M.; Valido, A. de La J.; Duarte, L. C.; Presmanes, K. F.; J. Appl. Phycol. 2011, 23, 7.

89. Schreiner, M.; Hulan, H. W.; J. Chromatogr., A 2004, 1045, 195.

90. Ackman, R. G.; Sipos, J. C.; J. Am. Oil Chem. Soc. 1964, 41, 377.

91. Gómez-Cortés, P.; Tyburczy, C.; Brenna, J. T.; Juárez, M.; De La Fuente, M. A.; J. Lipid Res. 2009, 50, 2412; Xu, R.; Mi, Y.; J. Am. Oil Chem. Soc. 2011, 88, 91 .

92. Kalogeropoulos, N.; Chiou, A.; Gavala, E.; Christea, M.; Andrikopoulos, N. K.; Food Res. Int. 2010, 43, 2006.

93. Qiul, J.; Fan, X.; Zou, H.; Chem. Technol. Fuels Oils 2011, 47, 102.

94. Suarez, P. A. Z.; Santos, A. L. F.; Rodrigues, J. P.; Alves, M. B.; Quim. Nova 2009, 32, 768.

95. Demirbas, A.; Energ. Convers. Manage. 2002, 43, 2349.

96. Johnson, M.; Wen, Z.; Energ. Fuel 2009, 23, 5179.

97. Vargas, J. V. C.; Carvalho Junior, R. M.; Ramos, L. P.; Marino, C. E. B.; Torres, J. C. L.; J. Chem. Technol. Biotechnol. 2011, 86, 1418.

98. Wahlen, B. D.; Willis, R. M.; Seefeldt, L. C.; Bioresour. Technol. 2011, 102,2724

99. Xu, R.; Mi, Y.; J. Am. Oil Chem. Soc. 2011, 88, 91.

100. Ng, K. Y. S.; Salley, S. O.; Kim, M.; Mohan, S.; DiMaggio, C.; Yan, S.; Top. Catal. 2010, 53,721; Santacesaria, E.; Trifuoggi, M.; D’Angelo, A.; Casale, L.; Tesse, R.; Di Serio, M.; Top. Catal. 2010, 53, 811; Ramos, L. P.; Wypych, F.; Silva, F. R.; Cordeiro, C. S.; Quim. Nova 2011, 34, 477; Sharma, Y. C.; Singh, B.; Korstad, J.; Fuel 2011, 90, 1309; Endalew, A. K.; Kiros, Y.; Zanzi, R.; Biomass Bioenerg. 2011, 35, 3787

101. Brian, J. K.; McNeff, C. V.; Yan, B.; Nowlan, D.; Bioresour. Technol. 2011, 102, 94.

102. Chen, Y-H.; Huang, B-Y.; Chiang, T-H.; Tang, T-C.; Fuel 2012, 94, 270.

103. Collet, M.; Hélias, A.; Lardon, L.; Ras, M.; Goy, R.; Steyer, J.-P.; Bioresour. Technol. 2011, 102, 207; Razon, L. F.; Tan, R. R.; Appl. Energy 2011, 88, 3507.

104. Associação Brasileira de Normas Técnicas; NBR ISO 14040: Gestão ambiental: Avaliação do ciclo de vida: Princípios e estrutura, Rio de Janeiro, 2009; Associação Brasileira de Normas Técnicas; NBR ISO 14044: Gestão Ambiental: Avaliação do ciclo de vida: Requisitos e Orientações, Rio de Janeiro, 2009.

105. Kaltschmitt, M.; Reinhardt, G. A.; Stelzer, T.; Biomass Bioenerg. 1997, 12, 121; Sheehan, J.; Camobreco, V.; Duffield, J.; Graboski, M.; Shapouri, H.; Life Cycle Inventory of Biodiesel and Petroleum Diesel for Use in an Urban Bus, U.S. Department of Agriculture and U.S. Department of Energy, 1998; UBA (Ed.) Umweltbundesamt-Texto 79/99, 1999, p. 17; Almeida Neto, J. A.; Cruz, R. S. da; Alves, J. M.; Pires, M. M.; Parente Júnior, E.; Anais do Congresso Brasileiro de Mamona, Campina Grande, Brasil, 2004; Kim, S.; Dale, B.; Biomass Bioenerg. 2005, 29 , 426.

106. Reinhardt, G.; Rettenmaier, N.; Köppen, S.; International Conference and Exhibition on Bioenerg, Guimarães, Portugal 2008; Kim, H.; Kim, S.; Dale, B. E.; Environ. Sci. Technol. 2009, 43, 961; United Nations Environment Programme; Towards Sustainable Production and Use of Resources: Assessing Biofuels, Paris, 2009.

107. Kim, S.; Dale, B.; Biomass Bioenerg. 2005, 29, 426.

108. Li, Q.; Du, W.; Liu, D.; Appl. Microbiol. Biotechnol. 2008, 80, 749; Tabernero, A.; del Valle, E.; M. M.; Galán, M. A.; Biochem. Eng. J. 2012, $63,104$.

109. Sander, K.; Murthy, G. S.; Int. J. Life Cycle Assess. 2010, 15, 704; Anoop, S.; Olsen, S. I.; Appl. Energy 2011, 88, 3548; Sevigné Itoiz, E.; Fuentes-Grünewald, C.; Gasol, C. M.; Garcés, E.; Alacid, E.; Rossi, S.; Rieradevall, J.; Biom. Bioener. 2012, 39, 324.

110. Khoo, H. H.; Sharratt, P. N.; Das, P.; Balasubramanian, R.K.; Naraharisetti, P. K.; Shaik, S.; Bioresour. Technol. 2011, 102, 5800. 
111. Jorquera, O.; Kiperstok, A.; Sales, E. A.; Embiruçu, M.; Ghirardi, M. L.; Bioresour. Technol. 2010, 101, 1406.

112. Lardon, L.; Hélias, A.; Sialve, B.; Steyer, J.; Bernard, O.; Environ. Sci. Technol. 2009, 43, 6475 .

113. Xu, L.; Brilman, D.; Withag, J.; Brem, G.; Kersten, S.; Bioresour. Technol. 2011, 102, 5113.

114. Campbell, P. K.; Beer, T.; Batten, D.; Bioresour. Technol. 2011, 102, 50.

115. Harto, C.; Meyers, R.; Williams, E.; Energ. Policy 2010, 38, 4933.

116. Delrue, F.; Setier, P. A.; Sahut, C.; Cournac, L.; Roubaud A.; Peltier, G.; Froment, A. K.; Bioresour. Technol. 2012, 111, 191.
117. Wijffels, R. H.; Barbosa, M. J.; Science 2010, 329, 796.

118. Cheng, Y.; Lu, Y.; Gao, C.; Wu, Q.; Energ. Fuel 2009, 23, 4166; Gao, C.; Zhai, Y.; Ding, Y.; Wu, Q.; Appl. Energy 2010, 87, 756; Lu, Y.; Zhai, Y.; Liu, M.; Wu, Q.; J. Appl. Phycol. 2010, 22, 573; Xiong, W.; Gao, C.; Yan, D.; Wu, C.; Wu, Q.; Bioresour. Technol. 2010, 101, 2287.

119. Teixeira, C. M. L. L.; Morales, M. E.; Anais do I Congresso Brasileiro de Tecnologia de Biodiesel, Brasília, Brasil, 2006.

120. Ver Anais do $5^{\circ}$ Congresso Brasileiro de Tecnologia de Biodiesel e $8^{\circ}$ Congresso Brasileiro de Plantas Oleaginosas, Óleos, Gorduras e Biodiesel, Salvador, Brasil, 2012, Vols.1, 2 e 3. 